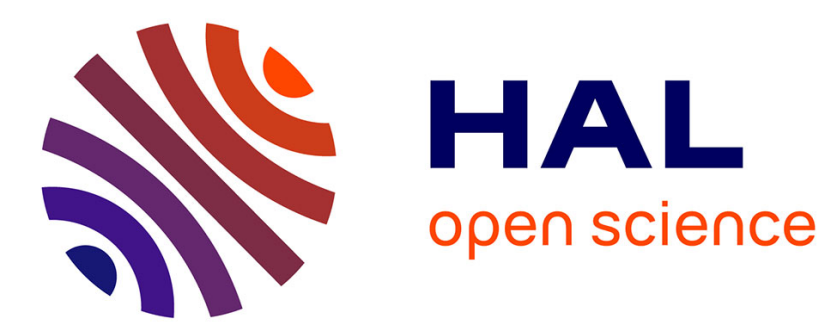

\title{
Wind Turbine Effects on VOR System Performance
}

Christophe Morlaas, M'Barek Fares, Bernard Souny

\section{To cite this version:}

Christophe Morlaas, M'Barek Fares, Bernard Souny. Wind Turbine Effects on VOR System Performance. IEEE Transactions on Aerospace and Electronic Systems, 2008, 44 (4), pp 1464-1476. 10.1109/TAES.2008.4667722 . hal-01067271

\section{HAL Id: hal-01067271 https://hal-enac.archives-ouvertes.fr/hal-01067271}

Submitted on 23 Sep 2014

HAL is a multi-disciplinary open access archive for the deposit and dissemination of scientific research documents, whether they are published or not. The documents may come from teaching and research institutions in France or abroad, or from public or private research centers.
L'archive ouverte pluridisciplinaire HAL, est destinée au dépôt et à la diffusion de documents scientifiques de niveau recherche, publiés ou non, émanant des établissements d'enseignement et de recherche français ou étrangers, des laboratoires publics ou privés. 


\section{Wind Turbine Effects on VOR System Performance}

\section{MORLAAS}

ENAC, Civil Aviation National School

\section{FARES}

CERFACS, European Center for Research and Advanced Training in Scientific Computation

\section{B. SOUNY}

ENAC, Civil Aviation National School

The implementation of wind farms establishment in France is increasing. When wind farms are located close to radionavigation systems, it becomes important to evaluate their electromagnetic effects on existing radionavigation instalations. In this study, the radionavigation system is a VOR (VHF omnidirectional radio) operating at about $110 \mathrm{MHz}$.

Because rotor blades are made of a balsa and dielectric multilayers composition, their electromagnetic behavior differs from that of metal blades at VHF frequences. In this study, we first obtain an electromagnetic CAD model from a real structural design; then we calculate the far field scattering matrix from an integral method (CESC code [1] method of moment) for a (30 $\mathrm{m})$ dielectric blade and compare it with a metal one using RCS (radar cross section) calculation.

The impact of (40 m long) dielectric blades is compared with the $(65 \mathrm{~m}$ high) metal mast effect in terms of scattered field, and then the VOR error (bearing error) is evaluated. These results are analyzed for several geometrical configurations of a three-bladed rotor and compared with the mast. The study is extended on wind farms to discuss geometrical configuration effects with regard to a VOR location.

Manuscript received December 8, 2006; revised June 20, 2007; released for publication October 10, 2008.

\section{IEEE Log No. T-AES/44/4/930725.}

Refereeing of this contribution was handled by M. S. Braasch.

Authors' addresses: M. Morlaas and B. Souny, ENAC, 7 Edouard Belin, BP 54005, 31055 Toulouse, Cedex 4, France, E-mail: (morlaas@recherche.enac.fr); M. Fares, European Center for Research and Advanced Training in Scientific Computation, Toulouse, France.

\section{INTRODUCTION}

Wind farm installations located close to radionavigation equipment like VHF omnidirectional radio (VOR) systems entail some operational risks. Electromagnetic interactions of the VOR signal with wind turbines can generate multipath rays in the receiver.

Depending on the importance of the phenomenon, some azimuth direction shift may occur in the VOR receiver. If the total bearing error rises above $3^{\circ}$, the service is no longer available.

The goal of this study is double. First we built a CAD model of a dielectric blade at VHF frequences according to the manufacturer's specifications [3] and secondly, we quantified the impact of the wind farm on conventional and Doppler VOR accuraces.

Technical examinations of wind turbine effects on radio frequency services such as TV receivers $[8,10]$, and radar systems $[5,9,7]$ have already been assessed. All these works used metal blade structures in their study.

Since rotor blades are manufactured from composite materials, their electromagnetic behavior is highly frequency dependent. Until now, detailed studies of VOR systems in the presence of dielectric blades have not been made.

In this work, we first built a geometrical CAD model with internal simplification accordingly to electromagnetic considerations in the VHF band as described in Section II. The metal blade model is then compared with the dielectric one in terms of radar cross section (RCS) in Section III.

In order to obtain accurate results, the method of moment requires that the geometrical structure be subdivided with edges shorter than $\lambda / 5$. This implies small $(30 \mathrm{~m})$ blade structures due to in-core computing memory constraints. To overcome this difficulty, we built a new geometrical blade model (called simplified model) and have compared it with the full validated model in Section IV.

The description of the VOR bearing error calculation for different multipaths is reported in Section V.

In Section VI, the scattered electrical field and bearing error of a $40 \mathrm{~m}$ dielectric blade with a $65 \mathrm{~m}$ metal mast are compared according to various criteria. We show the mast effect on VOR accuracy is dominating as compared with the blade effects.

Finally, several implementation configurations of wind farms are modeled.

\section{FULL DIELECTRIC BLADE CAD MODEL}

In order to accurately predict the blade's electromagnetic behavior, we built a full CAD model which takes into account the multilayered dielectric 

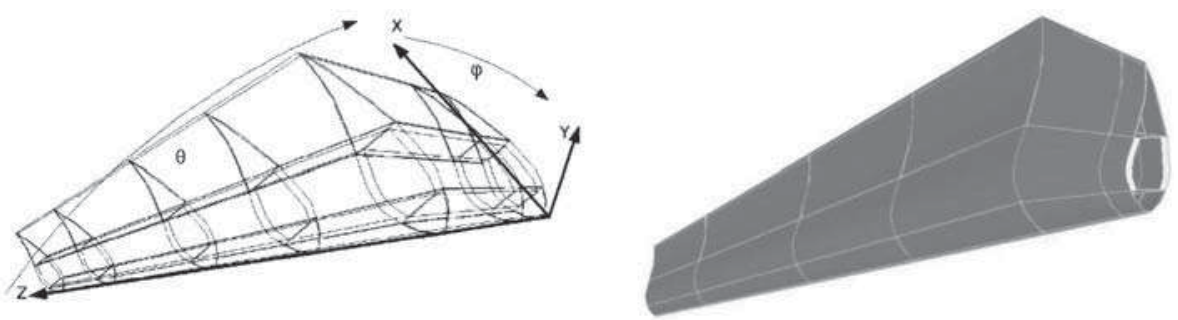

Fig. 1. 3D schema of full blade model.

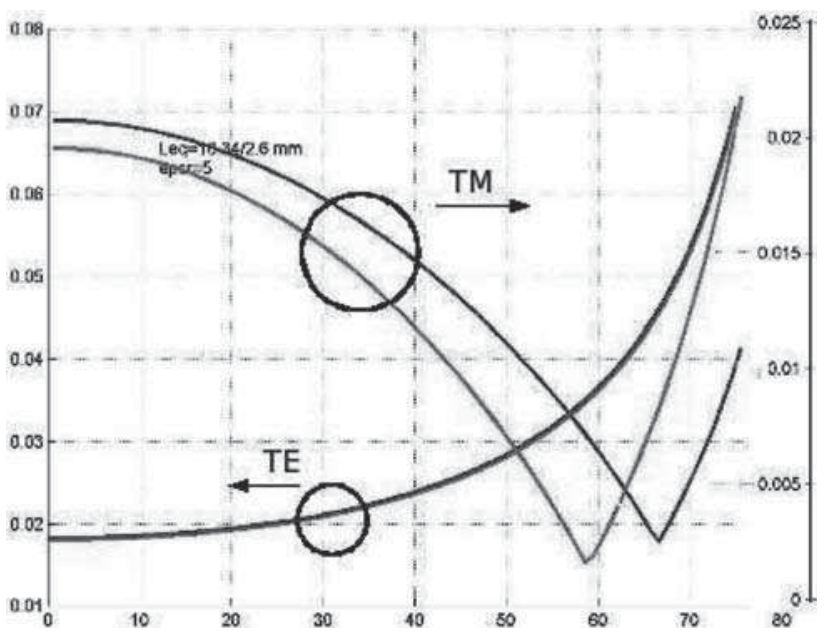

Fig. 2. Reflexion coefficient of multilayered (black curve) and single dielectric (clear curve) for TE (left axis) and TM (right axis) polarizations at $110 \mathrm{MHz}$.

and balsa structure of the blade. The physical dimensions of the blade are inspired by [3].

The external wind turbine dimensions are: blade length, $30 \mathrm{~m}$; mast length, $65 \mathrm{~m}$; mast base diameter, $3.2 \mathrm{~m}$; mast top diameter, $2.6 \mathrm{~m}$.

To perform the one blade modeling, we used an integral method ((CESC [1]) method of moment). Usually, to model objects whose dimensions are far bigger than a wavelength, asymptotic methods are used. In this case, the dielectric nature and hollow structure of the blades do not allow such methods unless blades are metal coated.

In order to simplify the multilayered structure study, we consider a homogeneous dielectric of an effective dielectric constant of 5 and reduce the thickness of the blade skin accordingly. The new calculated dimensions are shown in Table I (R0 and $c$ are the external blade dimensions according to the $\mathrm{z}$ and $\mathrm{x}$ axes, respectively) and the corresponding schematic is shown in Fig. 1. This model has been validated by the transfer and reflection coefficient calculation on a multilayered dielectric illuminated by a plane wave as shown by the superposition of curves in Fig. 2 for TE and TM polarizations.

This CAD model implies a 235 Gbyte memory for in-core computing for a $30 \mathrm{~m}$ long blade.
TABLE I

Blade Cross Section After Dielectric Modeling at 25\%/R0

\begin{tabular}{ccc}
\hline \hline Section/c & Dielectric Constant & Thickness $(\mathrm{mm})$ \\
\hline $0-15 \%$ & 5.00 & 4 \\
$15-50 \%$ & 5.00 & 44 \\
$50-100 \%$ & 5.00 & 5.3 \\
trailing-edge & 5.00 & 5.3 \\
\hline
\end{tabular}

\section{A METAL BLADE COMPARED WITH A DIELECTRIC ONE}

The dielectric blade is compared with a metal one which is usually used to model rotor blades.

The bi-static RCS results are represented in Figs. 3-6 for incident directions of: 1) $\theta_{\text {inc }}=0^{\circ}$, $\left.\left.\varphi_{\text {inc }}=0^{\circ}, 2\right) \theta_{\text {inc }}=90^{\circ}, \varphi_{\text {inc }}=90^{\circ}, 3\right) \theta_{\text {inc }}=135^{\circ}$, $\varphi_{\text {inc }}=0^{\circ}$ and for different observation directions, $\varphi_{\text {obs }}$ fixed and $\theta_{\text {obs }}$ varying. $\varphi_{\text {obs }}$ and $\theta_{\text {obs }}$ refer to the Cartesian coordinate system, in Figs. 1 and 7 where $\theta$ is the angle between the $\mathrm{z}$ axis and the $\mathrm{xy}$ plane and $\varphi$ is the angle between the $\mathrm{x}$ and $\mathrm{y}$ axes.

Some discrepancies between the two models at this frequency are observed, with a $25 \mathrm{~dB}$ maximum variation and a shifted maximum peak (Fig. 3(c)).

Thus, the metal model cannot be used to accurately model rotor blades at VHF frequences. Not only, in some directions the scattered field is overestimated (see Fig. 4(b)) but also in other ones it is underestimated (see Fig. 6, (a)) and does not have the same behavior.

\section{SIMPLIFIED CAD MODEL}

In order to model longer blades and to reduce the in-core memory used for processing, we ignore the blade skin and keep the dielectric spar caps. Table I is then simplified to Table II. The new simplified CAD model is shown in schematic 7 . This simplified model reduces the in-core memory used fivefold.

The RCS results are compared with those using the full CAD model of the blade.

The RCS results are represented in Figs. 5-11 for incident directions of: 1) $\theta_{\text {inc }}=0^{\circ}, \varphi_{\text {inc }}=0^{\circ}, 2$ ) $\left.\theta_{\text {inc }}=90^{\circ}, \varphi_{\text {inc }}=90^{\circ}, 3\right) \theta_{\text {inc }}=135^{\circ}, \varphi_{\text {inc }}=0^{\circ}$ and for different observation directions. 


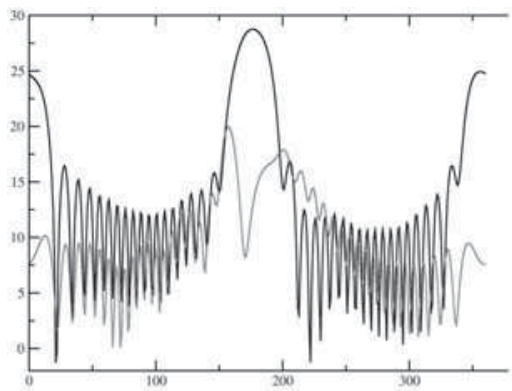

(a)

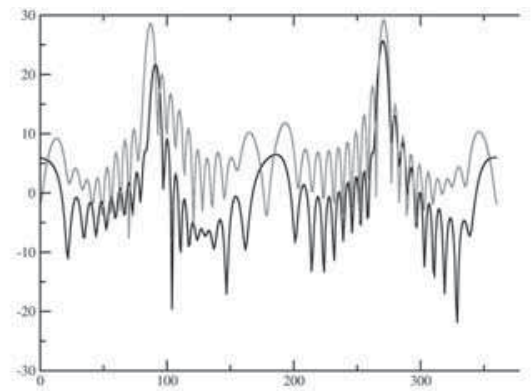

(b)

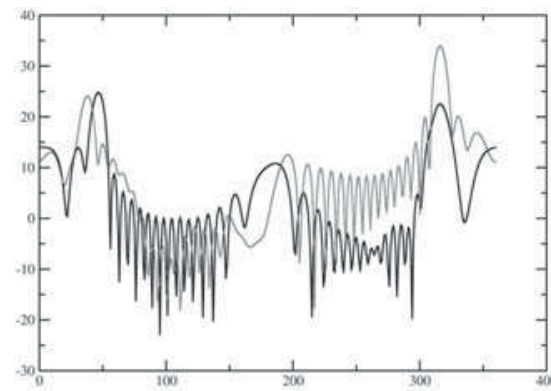

(c)

Fig. 3. RCS $\left(\mathrm{dB} / \mathrm{m}^{2}\right)$ of metal and dielectric blade for $\hat{\theta}$ polarization, $\varphi_{\mathrm{obs}}=0^{\circ}$ (full dielectric blade $=$ solid line, metal blade $=$ dotted line). (a) Incident direction: $\theta=0, \varphi=0$. (b) Incident direction: $\theta=90, \varphi=90$. (c) Incident direction: $\theta=135, \varphi=0$.

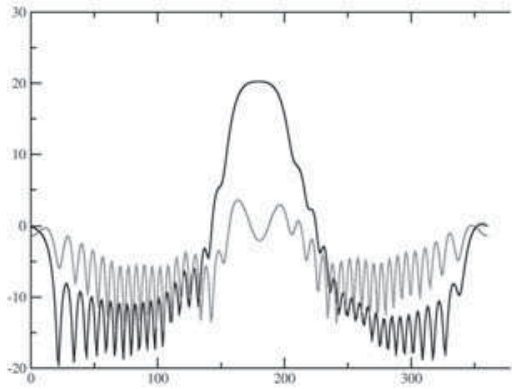

(a)

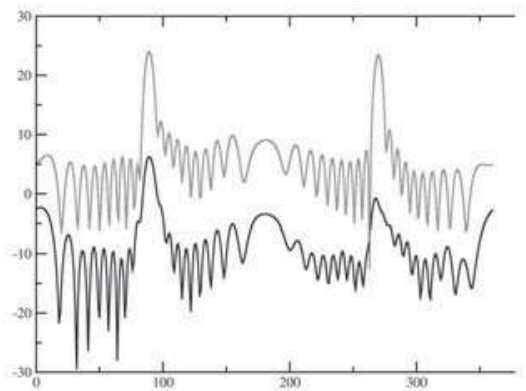

(b)

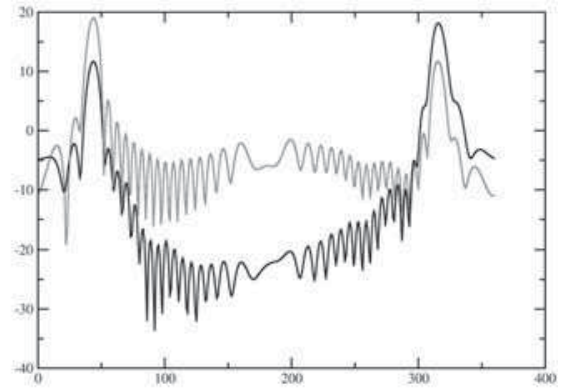

(c)

Fig. 4. RCS $\left(\mathrm{dB} / \mathrm{m}^{2}\right)$ of metal and dielectric blade for $\hat{\varphi}$ polarization, $\varphi_{\mathrm{obs}}=0^{\circ}$ (full dielectric blade $=$ solid line, metal blade $=$ dotted line). (a) Incident direction: $\theta=0, \varphi=0$. (b) Incident direction: $\theta=90, \varphi=90$. (c) Incident direction: $\theta=135, \varphi=0$.

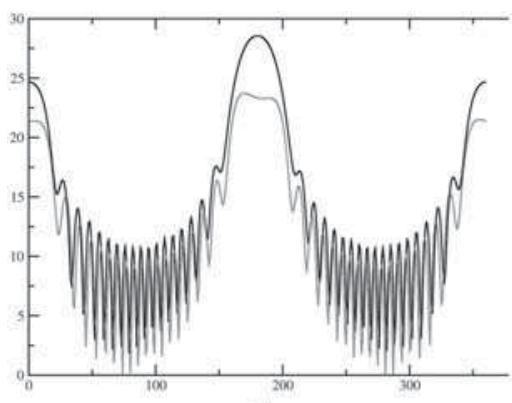

(a)

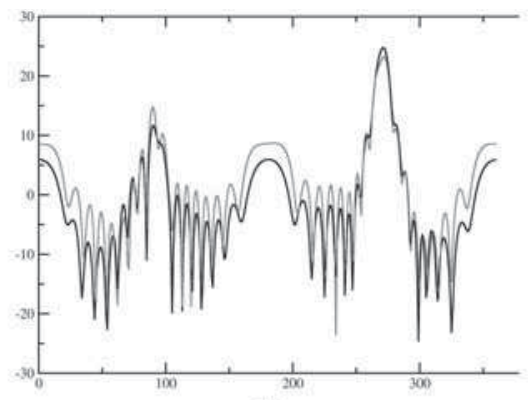

(b)

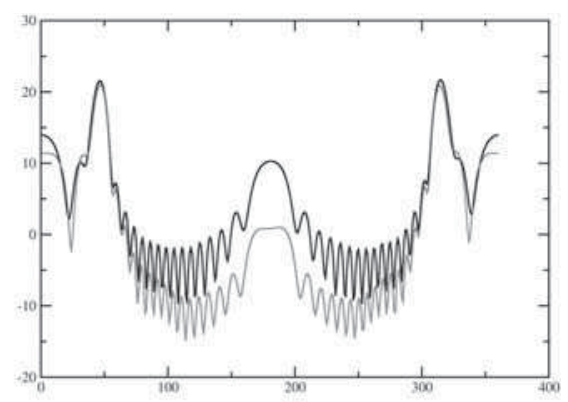

(c)

Fig. 5. RCS $\left(\mathrm{dB} / \mathrm{m}^{2}\right)$ of metal and dielectric blade for $\hat{\theta}$ polarization, $\varphi_{\mathrm{obs}}=90^{\circ}$ (full dielectric blade $=$ solid line, metal blade $=$ dotted line). (a) Incident direction: $\theta=0, \varphi=0$. (b) Incident direction: $\theta=90, \varphi=90$. (c) Incident direction: $\theta=135, \varphi=0$.

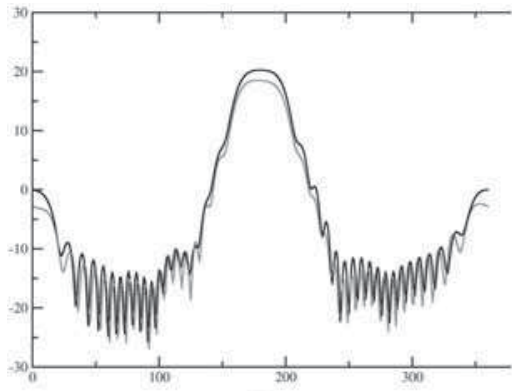

(a)

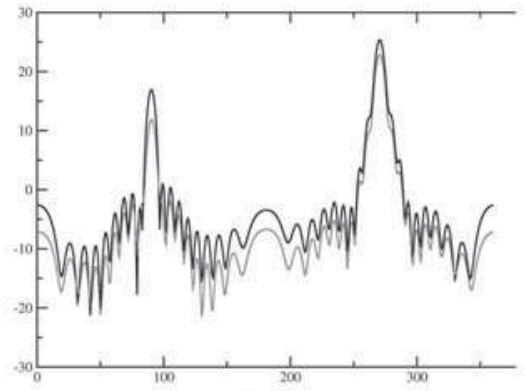

(b)

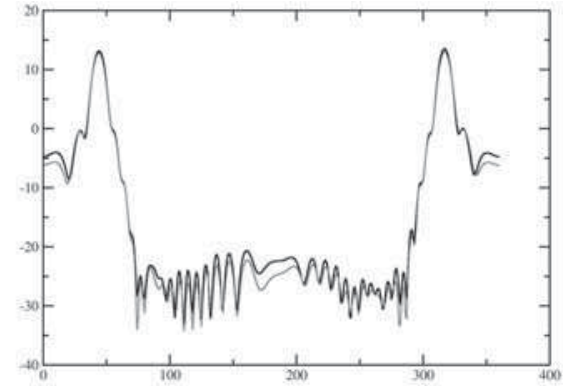

(c)

Fig. 6. RCS $\left(\mathrm{dB} / \mathrm{m}^{2}\right)$ of metal and dielectric blade for $\hat{\varphi}$ polarization, $\varphi_{\mathrm{obs}}=90^{\circ}$ (full dielectric blade $=$ solid line, metal blade $=$ dotted line). (a) Incident direction: $\theta=0, \varphi=0$. (b) Incident direction: $\theta=90, \varphi=90$. (c) Incident direction: $\theta=135, \varphi=0$. 

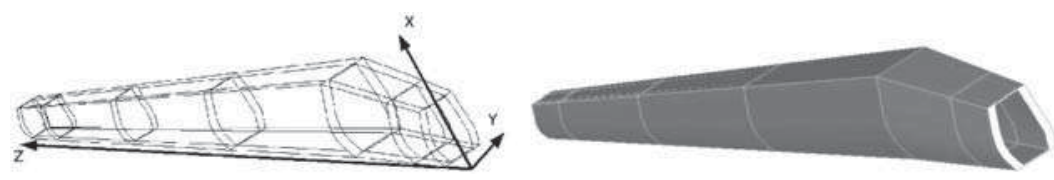

Fig. 7. 3D schema of simplified blade model.

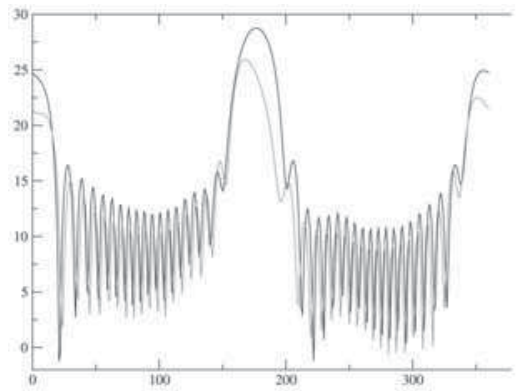

(a)

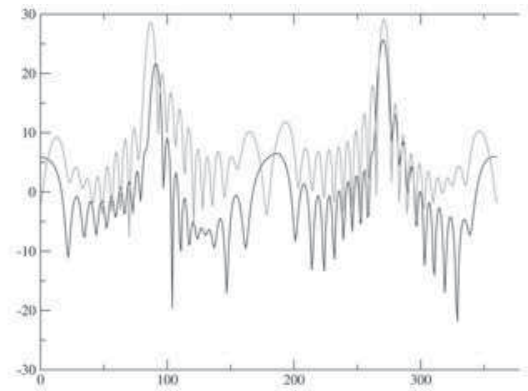

(b)

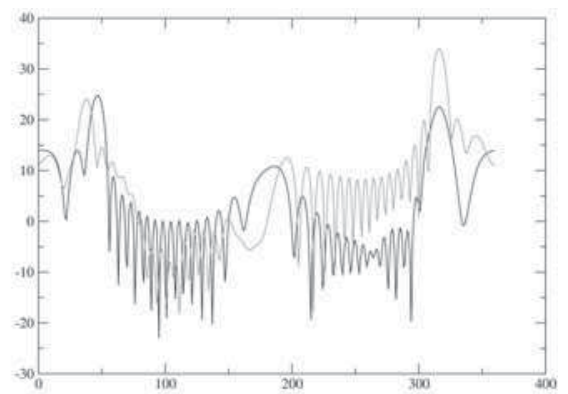

(c)

Fig. 8. RCS $\left(\mathrm{dB} / \mathrm{m}^{2}\right)$ of simplified and dielectric blade for $\hat{\theta}$ polarization, $\varphi_{\mathrm{obs}}=0^{\circ}$ (full dielectric blade $=$ solid line, Simplified dielectric blade $=$ dotted lin). (a) Incident direction: $\theta=0, \varphi=0$. (b) Incident direction: $\theta=90, \varphi=90$. (c) Incident direction: $\theta=135, \varphi=0$.

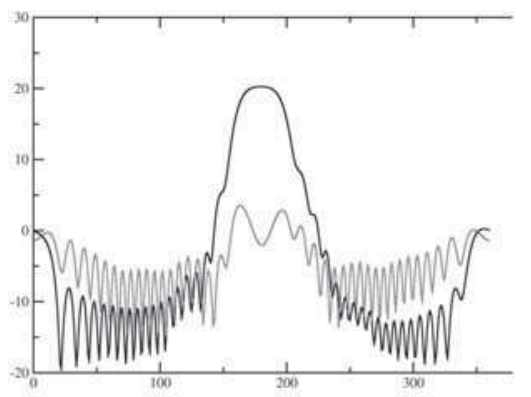

(a)

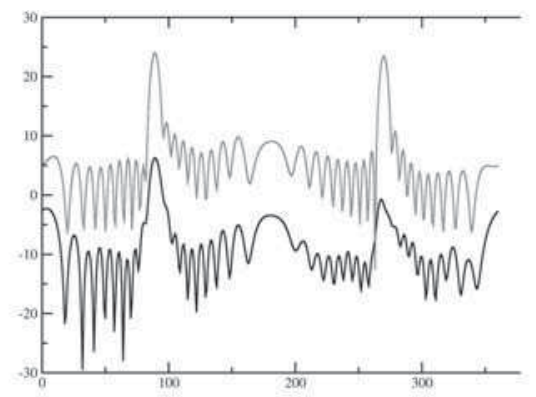

(b)

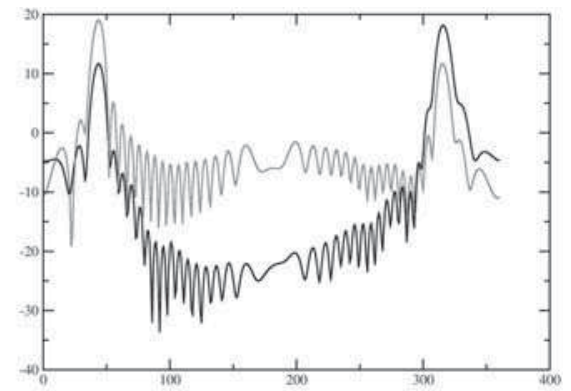

(c)

Fig. 9. RCS $\left(\mathrm{dB} / \mathrm{m}^{2}\right)$ of simplified and dielectric blade for $\hat{\varphi}$ polarization, $\varphi_{\mathrm{obs}}=0^{\circ}$ (full dielectric blade $=$ solid line, Simplified dielectric blade $=$ dotted line). (a) Incident direction: $\theta=0, \varphi=0$. (b) Incident direction: $\theta=90, \varphi=90$. (c) Incident direction: $\theta=135$, $\varphi=0$.

TABLE II

Simplified Blade Cross Section at $25 \% / \mathrm{R} 0$

\begin{tabular}{ccc}
\hline \hline Section/c & Dielectric Constant & Thickness (mm) \\
\hline $15-50 \%$ & 5.00 & 44 \\
\hline
\end{tabular}

Good agreement between the two models is observed, with a maximum discrepancy of $9 \mathrm{~dB}$ as shown in Figs. 8(c) and 10(c), for $\theta_{\mathrm{obs}}=180^{\circ}$

Although, these discrepances are localized at some observation directions, these are considered while multiplying the scattered field by 2.8 in all observation directions (worst case).

This new CAD model requires a 47 Gbyte in-core memory for the calculation of a $30 \mathrm{~m}$ long blade. Then a $40 \mathrm{~m}$ long blade is modeled for the calculation of the VOR bearing error.

\section{VOR ACCURACY (BEARING ERROR)}

To estimate the VOR accuracy, we have made use of the study from [4]. Because the VOR system uses a horizontal polarization, we need the $\hat{\phi}$ polarization component of the electrical field for each multipath as well as for the direct field in the VOR coordinate system.

For a single wind turbine we consider a three blade and mast scattering as being a single multipath by vectorial summation of each scattered electrical field in the VOR coordinate system based on the calculation of their own scattered fields in their own coordinate systems.

In the aim to obtain general results, the nacelle is not modeled because this shape and this height can vary between different models of wind turbines. This electromagnetic modeling presents no difficulties since it's a metallic object with small dimensions. However, for big nacelles (rectangular or rounded) their electromagnetic effects on VOR bearing error are the same order of magnitude than ones of blades and should be investigated for specific models of wind turbines (see note 1 for a comparison between the effects of a rounded and a rectangular nacelle $(8 \mathrm{~m} * 3 \mathrm{~m})$ and a mast and three blades $)$. 


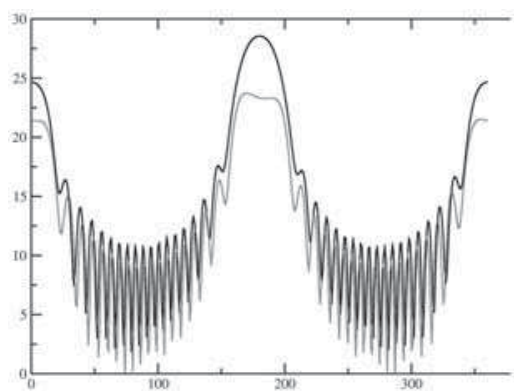

(a)

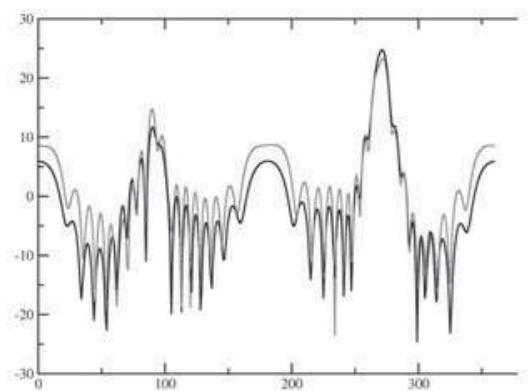

(b)

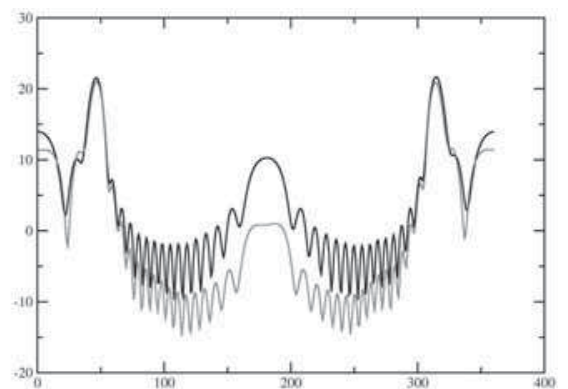

(c)

Fig. 10. RCS $\left(\mathrm{dB} / \mathrm{m}^{2}\right)$ of simplified and dielectric blade for $\hat{\theta}$ polarization, $\varphi_{\text {obs }}=90^{\circ}$ (full dielectric blade $=$ solid line, Simplified dielectric blade $=$ dotted line). (a) Incident direction: $\theta=0, \varphi=0$. (b) Incident direction: $\theta=90, \varphi=90$. (c) Incident direction: $\theta=135$, $\varphi=0$.

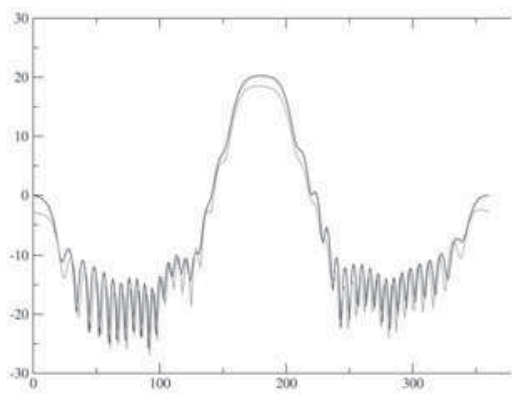

(a)

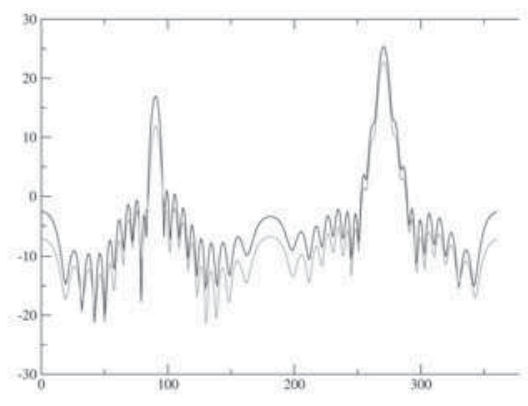

(b)

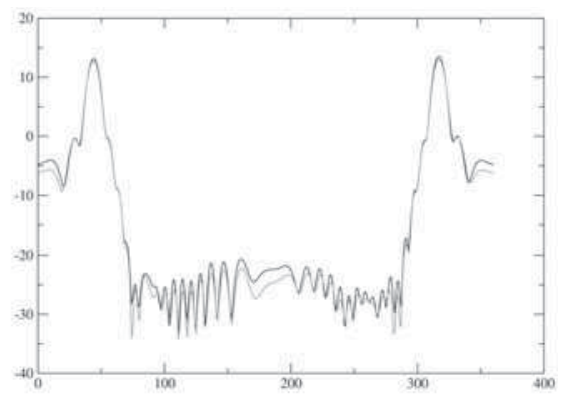

(c)

Fig. 11. RCS $\left(\mathrm{dB} / \mathrm{m}^{2}\right)$ of simplified and dielectric blade for $\hat{\varphi}$ polarization, $\varphi_{\mathrm{obs}}=90^{\circ}$ (full dielectric blade $=$ solid line, Simplified dielectric blade $=$ dotted line). (a) Incident direction: $\theta=0, \varphi=0$. (b) Incident direction: $\theta=90, \varphi=90$. (c) Incident direction: $\theta=135$, $\varphi=0$.

For VOR accuracy calculation, the disturbed signal is the variable one because the reference signal is omnidirectionally radiated and the $30 \mathrm{~Hz}$ modulating signal is too low in frequency to be impacted by multipath for the distances considered [4].

\section{A. Accuracy of a Conventional VOR}

The expression of the conventional VOR bearing error is written as follows:

$$
\begin{aligned}
\epsilon_{a c} & =\psi-\varphi_{0} \\
& =\tan ^{-1}\left(\sum_{i=1}^{N} \frac{A_{i}^{\prime} \sin \left(\varphi_{i}-\varphi_{0}\right) \cos \left(\theta_{i}-\theta_{0}\right)}{1+A_{i}^{\prime} \cos \left(\varphi_{i}-\varphi_{0}\right) \cos \left(\theta_{i}-\theta_{0}\right)}\right)
\end{aligned}
$$

with $A_{i}^{\prime}=a_{i} / a_{0}=A_{i} r_{0} / r_{i} A_{0}$ the scattering coefficient between direct and scattered signals

It only depends on the azimuth angle difference between the scatterer object (wind turbine) and the receiver (direct signal) from the VOR, the $\mathrm{RF}$ phase difference between the scattered signal and the direct one, and the scatterer's scattering coefficient:

$\omega \quad$ angular frequency VHF (100 MHz)

$\omega^{\prime} \quad$ angular frequency of subcarrier $(9960 \mathrm{~Hz})$ angular frequency $\mathrm{BF}(30 \mathrm{~Hz})$

true azimuth angle/North $i$ th azimuth angle of scatterer/North RF phase difference of direct path RF phase difference of $i^{t h}$ multipath amplitude modulation depth $(m=30 \%)$ frequency modulation depth $(n=16)$ direct signal amplitude $i$ th multipath amplitude received signal; $E_{\text {référencé réflechi }}^{\text {diriable }}$ measured azimuth with multipaths for conventional VOR measured azimuth with multipaths for Doppler VOR.

\section{B. Accuracy of a Doppler VOR}

The expression of the Doppler VOR bearing error is written as follows:

$$
\begin{aligned}
\epsilon_{a d} & =\beta-\varphi_{0} \\
& =\tan ^{-1}\left(\frac{\sum_{i=1}^{N} 2 \rho_{i} J_{1}\left(2 n \sin \left(\varphi_{i}^{\prime} / 2\right)\right) \cos \left(\varphi_{i}^{\prime} / 2\right)}{n-\sum_{i=1}^{N} 2 \rho_{i} J_{1}\left(2 n \sin \left(\varphi_{i}^{\prime} / 2\right)\right) \sin \left(\varphi_{i}^{\prime} / 2\right)}\right)
\end{aligned}
$$


with $\varphi_{i}^{\prime}=\varphi_{i}-\varphi_{0}$, and $\rho_{i}=a_{i} \cos \left(\theta_{i}-\theta_{0}\right)$ and with $a_{1}=A_{1} r_{0} / A_{0} r_{1}$ the scattering coefficient between the direct and the scattered signals.

It depends solely on the azimuth angle difference between the scatterer object (wind turbine) and the receiver (direct signal) from VOR, the RF phase difference between the scattered signal and the direct one, the scatterer's scattering coefficient, and the frequency modulation depth $(n)$.

\section{Doppler Effect by the Rotation of Blades}

According to (1) and (2), it can be shown that the Doppler frequency shift caused by the rotation of blades on a VHF signal is added to the cosine of the RF phase shift. Thus, it has no consequence on the absolute value of the VOR accuracy, but it only modulates the bearing error level at Doppler frequencies. effect:

Bearing error for conventional VOR with Doppler $\epsilon_{a c}($ with Doppler)

$$
=\psi-\varphi_{0}=A_{1} \sin \left(\varphi_{1}-\varphi_{0}\right) \cos \left(\theta_{1}-\theta_{0}+\theta_{\text {Doppler }}\right) .
$$
effect:

Bearing error for Doppler VOR with Doppler

$$
\begin{aligned}
& \epsilon_{a d}(\text { with Doppler }) \\
& =\beta^{6}-\varphi_{0}=\frac{1}{8} a_{1} \cos \left(\theta_{i}-\theta_{0}+\theta_{\text {Doppler }}\right) \\
& \quad \times J_{1}\left(2 n \sin \left(\left(\varphi_{1}-\varphi_{0}\right) / 2\right)\right) \cos \left(\left(\varphi_{1}-\varphi_{0}\right) / 2\right) .
\end{aligned}
$$

\section{BEARING ERROR CALCULATION AND RESULTS}

\section{A. Calculation Hypothesis}

1) The complex scattered field of a single dielectric blade is calculated (using CESC) for a far field assumption with a plane wave excitation and for two orthogonal polarizations. However this method is not restrictive to the far field area and can be easily extended to all areas. (See Note 2).

2) The scattered field of a mast is calculated (using CESC) with an optimized integral method for rotational invariant geometry with the same assumptions as the ones mentioned earlier.

3) The scattered matrix for a single mast and a single blade is then obtained for all possible incident and observation directions. A particular scene composed of a (Doppler or conventional) VOR, one or several wind turbines, and several receivers is built. The corresponding scattered far field from each wind turbine is then calculated from the scattering matrix calculated by CESC and multiplied by the far field terms $e^{j . K \text { Robs }} /$ Robs and $e^{j . K \text { Rinc }} /$ Rinc for the incident and scattered fields, respectively (Robs and Rinc are

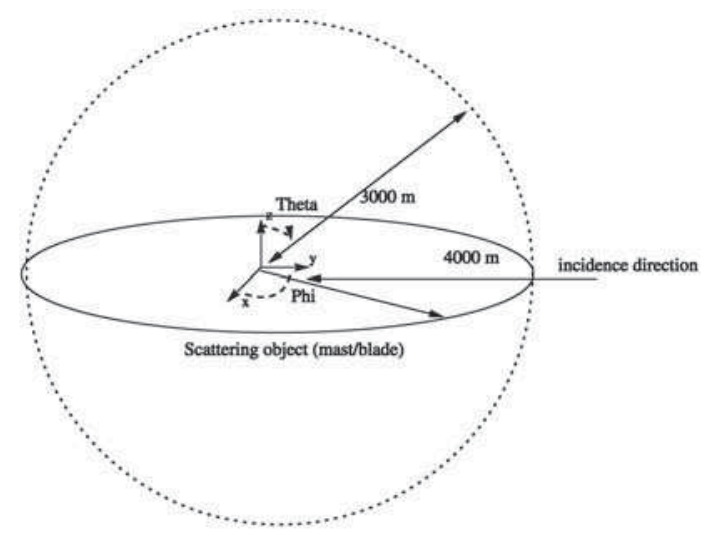

Fig. 12. Geometrical configuration.

the distances from the wind turbine to the receiver and VOR, respectively).

4) The VOR antenna radiating diagram is omnidirectional which is a worst case assumption. (See Note 3).

5) The VOR antenna receiving diagram is omnidirectional.

6) The multiple scatterings have not been taken into account (blade/blade, blade/mast, wind turbine/wind turbine). (See Note 4).

\section{B. Impact of a Dielectric Blade Compared with a Metal Mast Effect}

Now, a scene where both the VOR and the receiver are in the far field region of the wind turbine is considered. So the total scattered field of a wind turbine (mast and tree-bladed rotor) and for a mast are compared.

Scene description: $\theta_{\text {obs }}$ varying from 0 to $360^{\circ}$ according to the wind turbine reference coordinate system described in

Fig. 12:

for $\varphi_{\text {obs }}$ angle fixed to $90^{\circ}$ (Fig. 13).

for $\varphi_{\text {obs }}$ angle fixed to $45^{\circ}$ (Fig. 14). $\varphi_{\text {obs }}$ varying from 0 to $360^{\circ}$ : for $\theta_{\text {obs }}$ angle fixed to $89^{\circ}$ (Fig. 15).

$\varphi_{\text {obs }}$ varying from 0 to $360^{\circ}$ : for $\theta_{\text {obs }}$ angle fixed to $70^{\circ}$ (Fig. 16).

The incident field is $(\hat{\phi})$ horizontally polarized and the incident direction, in wind turbine coordinate system, is $\theta_{\text {inc }}=90^{\circ}, \varphi_{\text {inc }}=90^{\circ}$.

The VOR is $4000 \mathrm{~m}$ away from the wind turbine and the receivers are $3000 \mathrm{~m}$ away from the wind turbine with respect to the far field criteria where the plane wave incident assumption can apply.

The scattered far field from VOR reference coordinate system and the bearing error are then plotted for this configuration (Figs. 13-17) and for two rotor blade orientations (1 and 2) according to the Euler angle definition [2] and they are represented in 


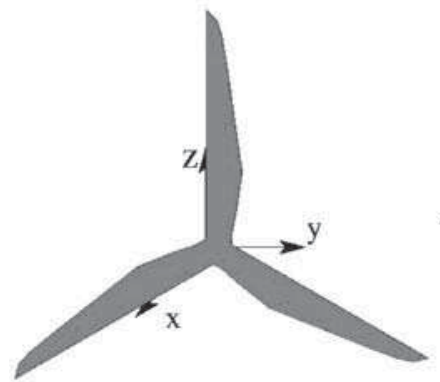

(a)

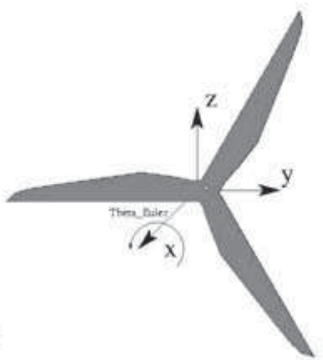

(b)

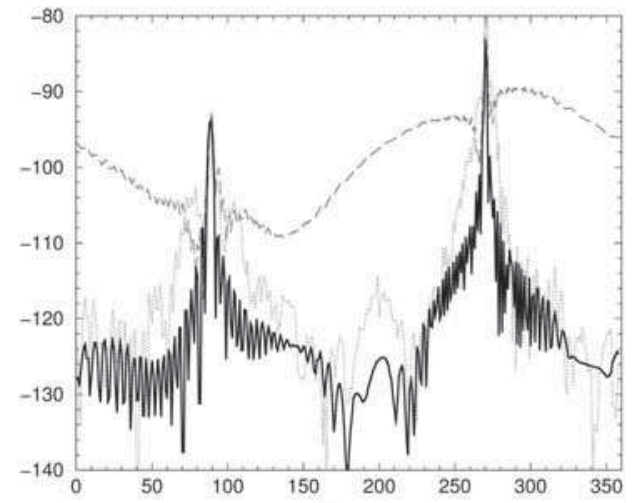

(c)

Fig. 13. Scattered field cut $(\mathrm{dBv} / \mathrm{m})$ of conventional VOR, $\varphi_{\mathrm{obs}}=90^{\circ}$ and $\theta_{\mathrm{obs}}=\left[0\right.$ to $\left.360^{\circ}\right]$. (Mast $=$ solid line. Mast + Tree_blades: orientation 1 = dotted line, orientation 2 = long dashed line). (a) Orientation 1. (b) Orientation 2. (c).
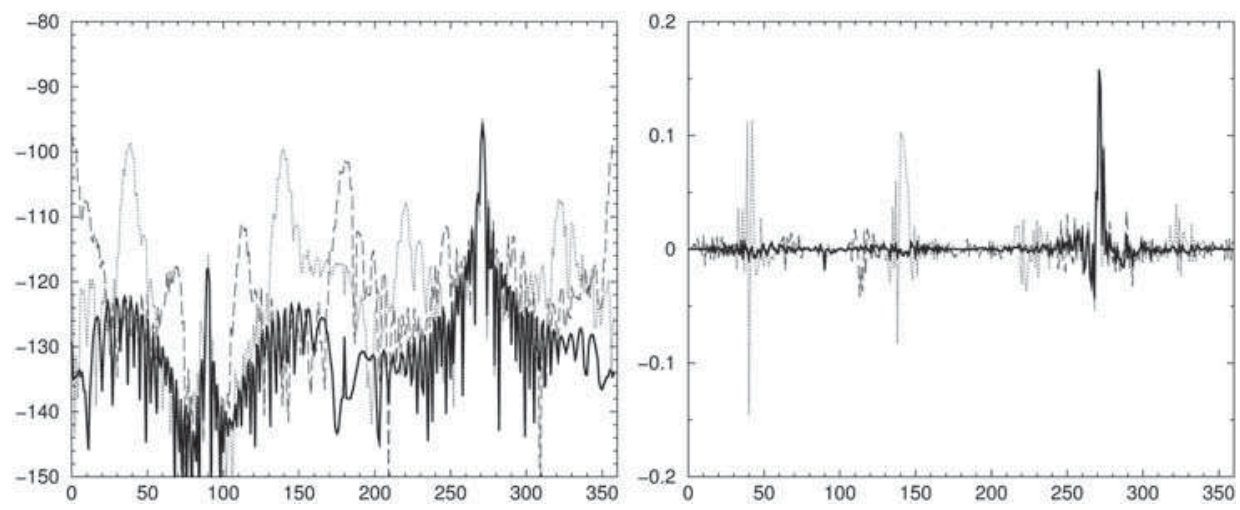

Fig. 14. Scattered field cut $(\mathrm{dBv} / \mathrm{m})$ and bearing error $\left(^{\circ}\right)$ of conventional VOR $\left({ }^{\circ}\right), \varphi_{\text {obs }}=45^{\circ}$ and $\theta_{\text {obs }}=\left[0\right.$ to $\left.360^{\circ}\right]$. (Mast $=$ solid line. Mast + Tree_blades: orientation $1=$ dotted line, orientation $2=$ long dashed line).
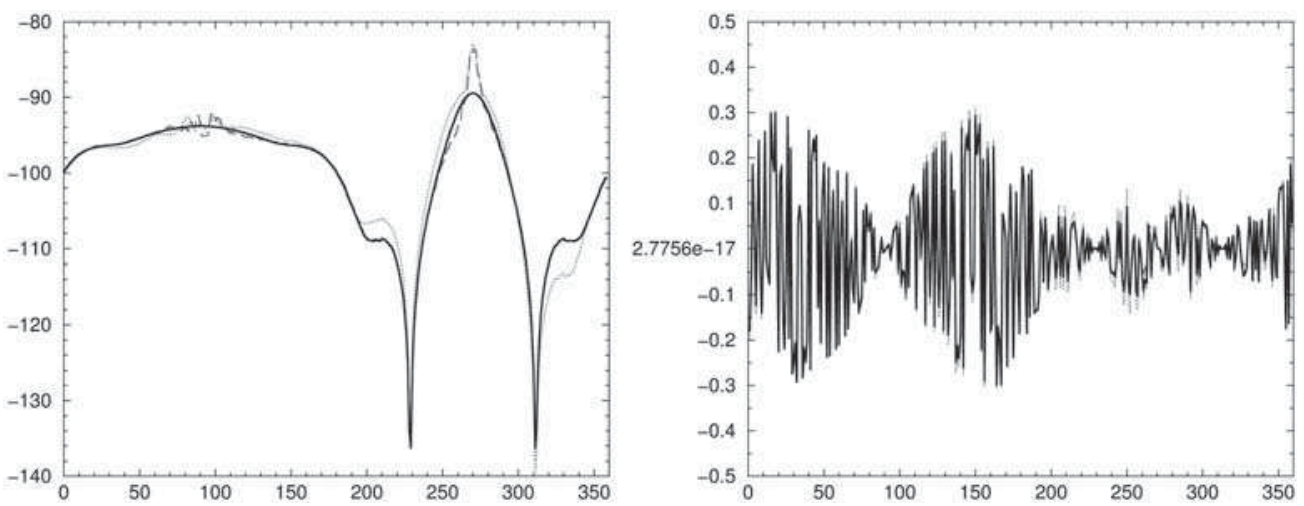

Fig. 15. Scattered field cut $(\mathrm{dBv} / \mathrm{m})$ and bearing error $\left({ }^{\circ}\right)$ of conventional VOR $\left({ }^{\circ}\right), \theta_{\mathrm{obs}}=89^{\circ}$ and $\varphi_{\mathrm{obs}}=\left[0\right.$ to $\left.360^{\circ}\right]$. (Mast $=$ solid line. Mast + Tree_blades: orientation $1=$ dotted line, orientation $2=$ long dashed line).

Fig. 13(a) and (b). The three-blade rotor is oriented toward the VOR (rotation along $\mathrm{z}$ axis is $90^{\circ}$ ).

In Figs. 13(c) and 14 a strong mast scattering at a site angle of about $2^{\circ}$, corresponding to the cone angle formed by the conical shape of the mast, is observed. In this region, the impact of the rotor blades is negligible compared with that of the mast as we can see in Fig. 15. The bearing error is mainly due to the mast scattering.
As can be seen in Fig. 13(c), the rotor blades field is stronger than that of the mast outside the $\theta_{\text {obs }}=89^{\circ}$ and $\theta_{\text {obs }}=271^{\circ}$ angle for \#2 rotor blade orientation (b). However, when the VOR, the scatterer and the receiver are azimuth aligned, the bearing error becomes null (see (1) and (2)).

Figs. 14 and 16, show that the rotor blade effects are no longer negligible compared with the mast effects. On the contrary, they dominate and we can 

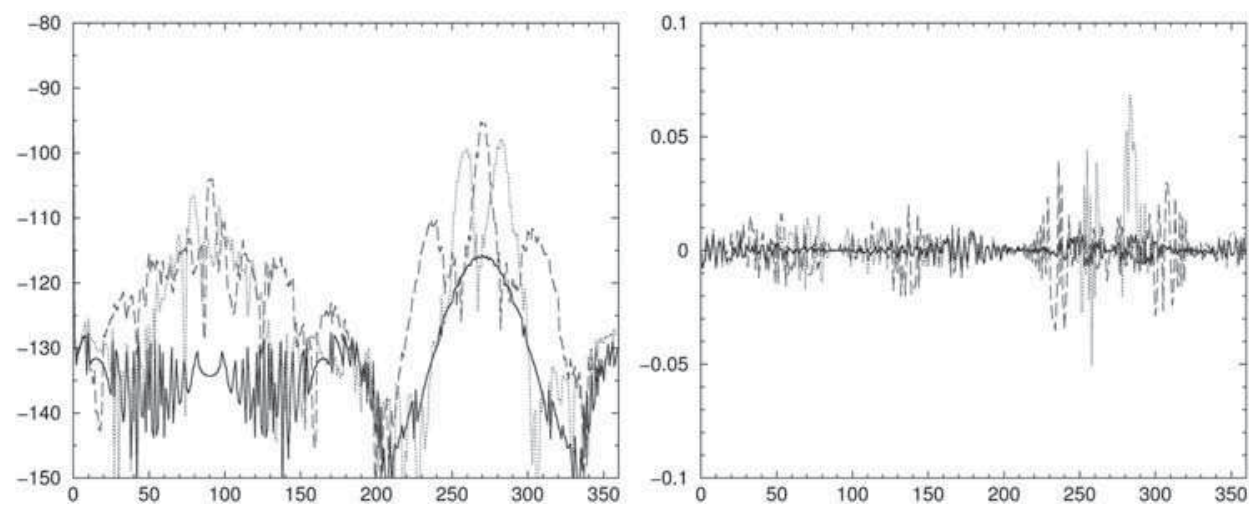

Fig. 16. Scattered field cut $(\mathrm{dBv} / \mathrm{m})$ and bearing error $\left(^{\circ}\right)$ of conventional VOR $\left(^{\circ}\right)$ for orientation $1, \theta_{\text {obs }}=70^{\circ}$ and $\varphi_{\text {obs }}=\left[0\right.$ to $\left.360^{\circ}\right]$. (Mast $=$ solid line. Mast + Tree_blades with $\mathrm{z}$ axis rotation: $0^{\circ}=$ dotted line, $45^{\circ}=$ dashed line, $90^{\circ}=$ long dashed line).

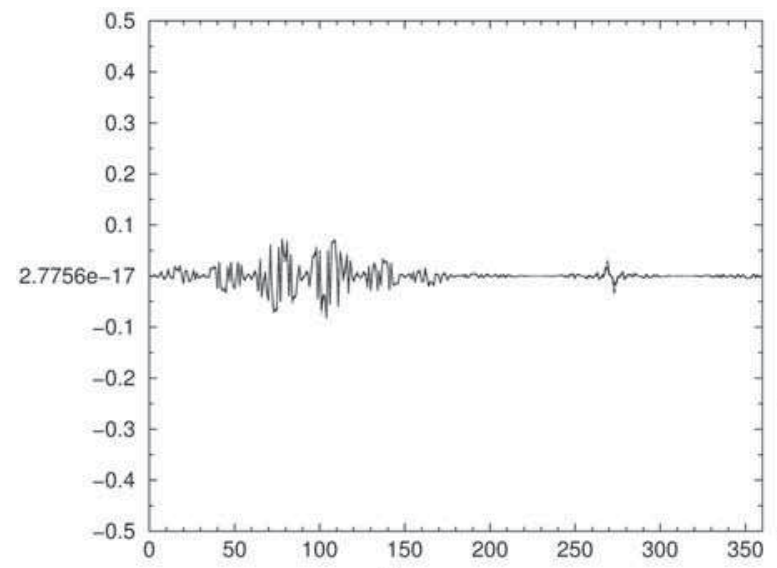

(a)

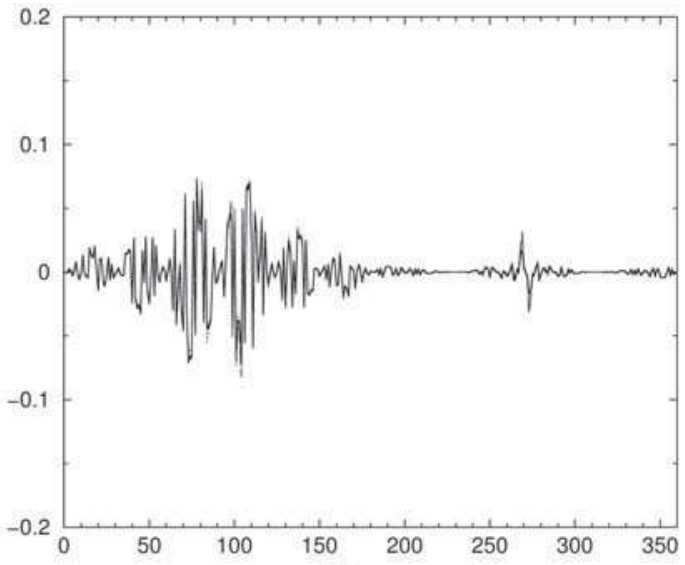

(b)

Fig. 17. Bearing error $\left({ }^{\circ}\right.$ ) of Doppler VOR (Mast $=$ solid line. Mast + Tree_blades: orientation $1=$ dotted line, orientation $2=$ long dashed line). (a) $\theta=89, \varphi=0-360^{\circ}$. (b) $\theta=0-360^{\circ}, \varphi=-45^{\circ}$.

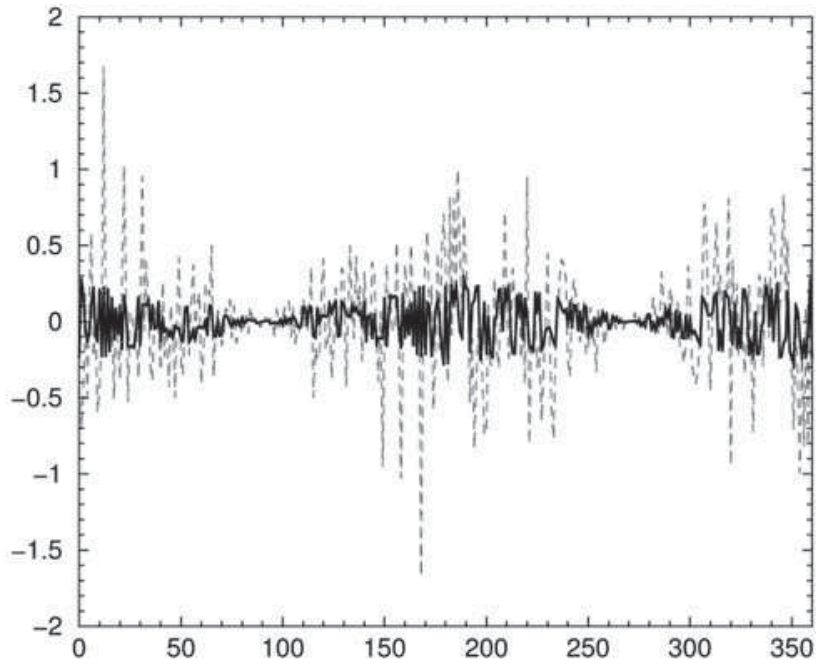

Fig. 18. 1 wind turbine $=$ black solid line, 9 wind turbines $=$ gray dotted line. $\theta=0-90^{\circ}$ by $0.5^{\circ}, \varphi=0^{\circ}$.

observe some bearing error peaks due solely to the blades. However these values are low enough to be harmless to the VOR system.

In Fig. 17, the bearing Doppler VOR error is plotted according to the two previous geometrical configurations (14 and 15). As expected, the Doppler bearing error is lower than the conventional one by about a ratio of 10 .

\section{Impact of the Number of the Wind Turbines}

A wind turbine is positioned at $5250 \mathrm{~m}$ from VOR and 9 wind turbines are centered at $5250 \mathrm{~m}$. The corresponding VOR bearing errors are compared in Fig. 18.

As expected from (1), the bearing error has a maximum error proportional to the number of the wind turbines and an average error increasing by the rms of the number of the wind turbines.

Here, the maximum theoretical increase is 9 and the maximum measured increase is about $1.7 / 0.25=$ 6.8. The theoretical average increase is 3 and the measured average increase is about 3 .

D. Impact of Wind Turbines with Respect to the VOR's Distance

A wind turbine is positioned at $5250 \mathrm{~m}$ from the VOR and another one at $7170 \mathrm{~m}$. The corresponding VOR bearing errors are described in Fig. 19. 


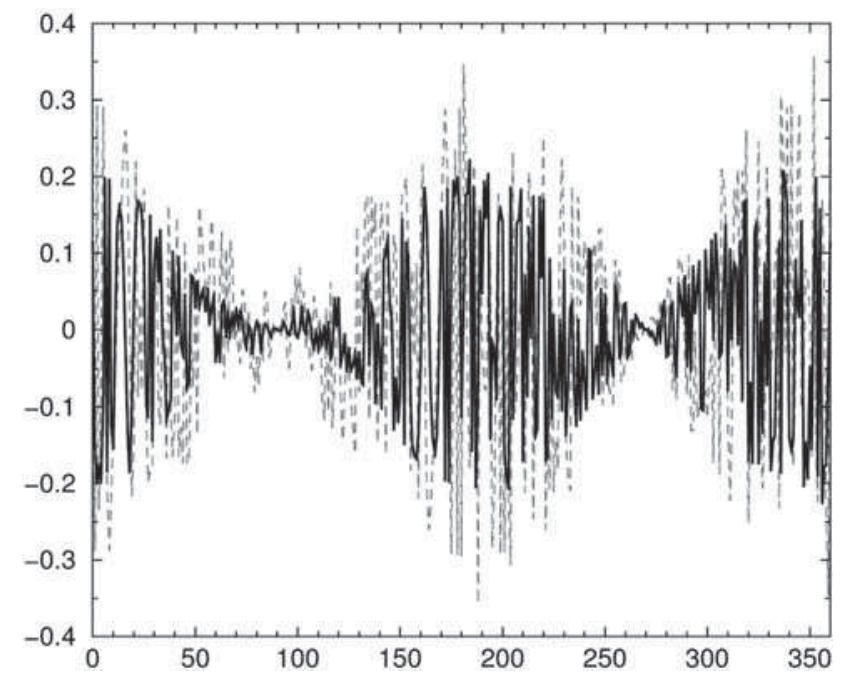

Fig. 19. 1 wind turbine at $5250 \mathrm{~m}=$ gray dashed line, 1 wind turbine at $7170 \mathrm{~m}=$ black solid line. $\theta=0-90^{\circ}$ by $0.5^{\circ}, \varphi=0^{\circ}$.

As expected from (1), the bearing error proportionally decreases with the distance of the wind turbine from the VOR since the electrical field decreases with distance as well.

The minimal theoretical decrease is about $7170 / 5250=1.36$; the maximum measured decrease is about $0.35 / 0.22=1.6$.

\section{E. Impact of the Implantation of a Wind Farm}

In this section several wind farm configurations of nine wind turbines are compared with each other and with a single one according to the scene described in Fig. 20. Each wind turbine creates a multipath in the receiver.

The bearing error for a conventional VOR is plotted in Fig. 21(b) for two wind farm orientations (Conf. 1: phi $=0^{\circ}$ ) one along the $\mathrm{x}$ axis centered at $y=5250 \mathrm{~m}$ and the other one (Conf. 2 : phi $=90^{\circ}$ )

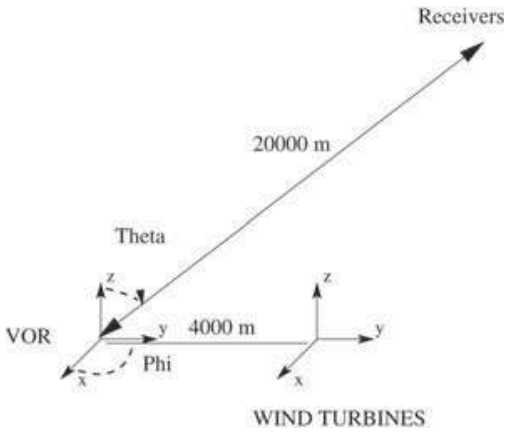

Fig. 20. Geometrical configuration.

along the $y$ axis centered at $y=5250 \mathrm{~m}$ as described in Fig. 21(a). All the wind turbines of this wind farm have the same (psi_Euler $=90) \mathrm{z}$ rotation axis and are randomly orientated along the $\mathrm{x}$ rotation axis. Wind turbines are spaced at $240 \mathrm{~m}$ intervals. The receivers are positioned $20 \mathrm{~km}$ away.

The VOR accuracy is at the same order of magnitude for these two implantation configurations, thus, they have no impact on the VOR accuracy. This is mainly due to fast variations of the RF phase between each multipath. The directions of the coherent recombinations are then very localized and seem to be random.

\section{F. 2D Representation}

In Figs. 22 and 23 the bearing error is plotted on a quarter of a sphere described by a receiver moving at a constant distance of $20 \mathrm{~km}$ for $\varphi_{\text {obs }}$ varying from 0 through $180^{\circ}$ and a site angle $\left(90-\theta_{\text {obs }}\right)$ varying from 0 through $45^{\circ}$ by $1^{\circ}$ steps. The wind farm is located $5250 \mathrm{~m}$ away from the VOR position.

The maximum error, positioned around a ring in the 0 to $10^{\circ}$ elevation angle, is due to the conical shape of the mast. For the upper angle, the lower error is due to the blade's multipaths. The maximum

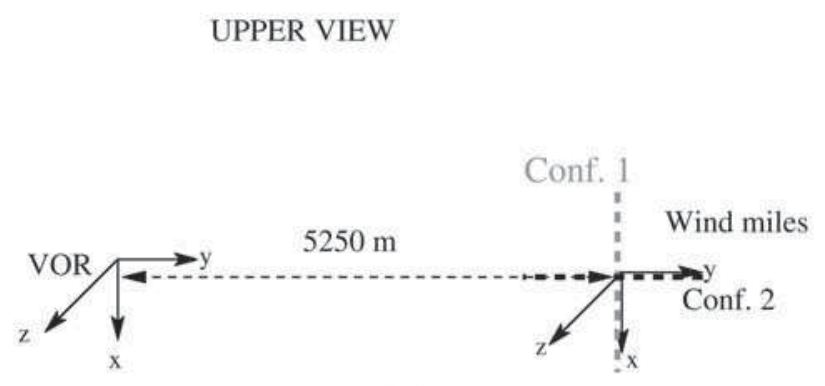

(a)

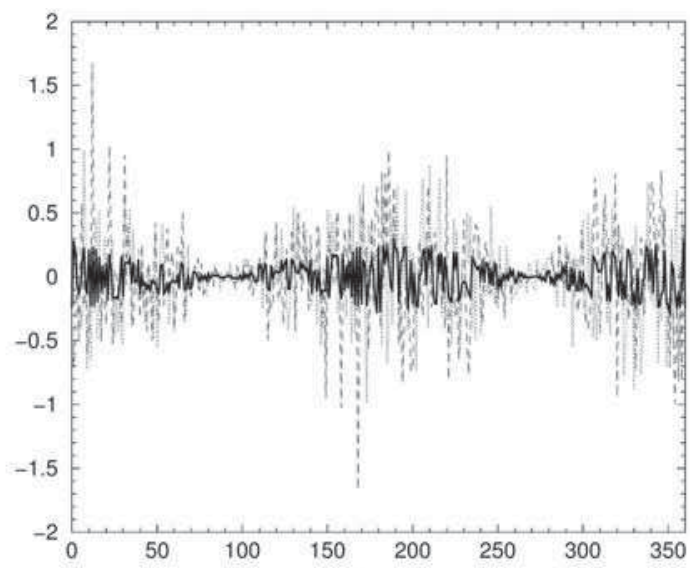

(b)

Fig. 21. Bearing error $\left({ }^{\circ}\right)$ of conventional VOR, $(1$ wind turbine $=$ black solid line, 9 wind turbines (Conf. 1 (dotted line), 2 (dashed line $)$ ) gray dotted line. (a) Geometrical configuration of wind farm implentation. (b) $\theta=88.5^{\circ}, \varphi=0-360^{\circ}$. 


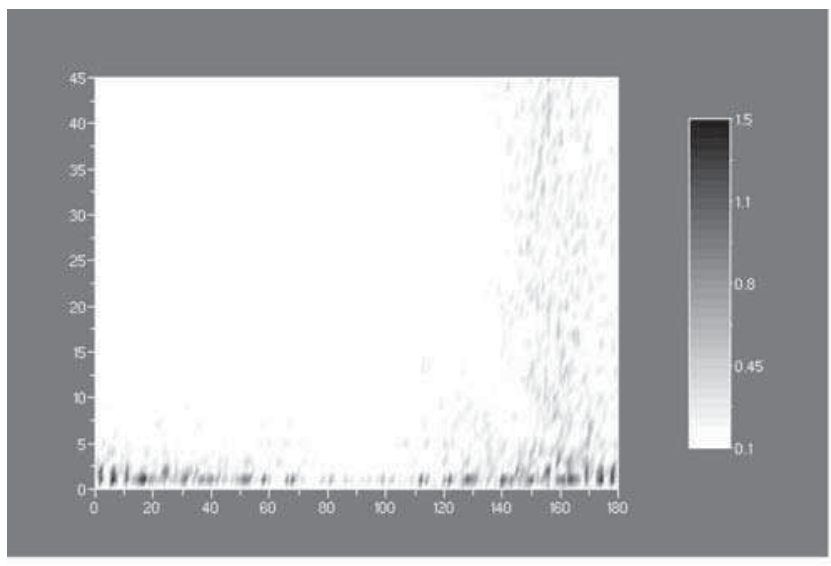

(a)

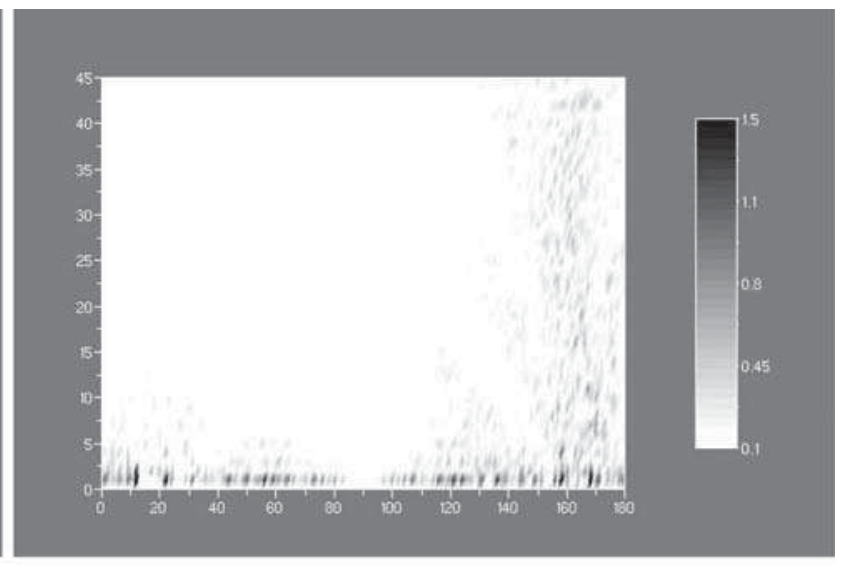

(b)

Fig. 22. VOR accuracy $\left({ }^{\circ}\right.$ ) of conventional VOR for two implantation configurations (Fig. 21(a)). (a) Conf. 1. (b) Conf. 2.

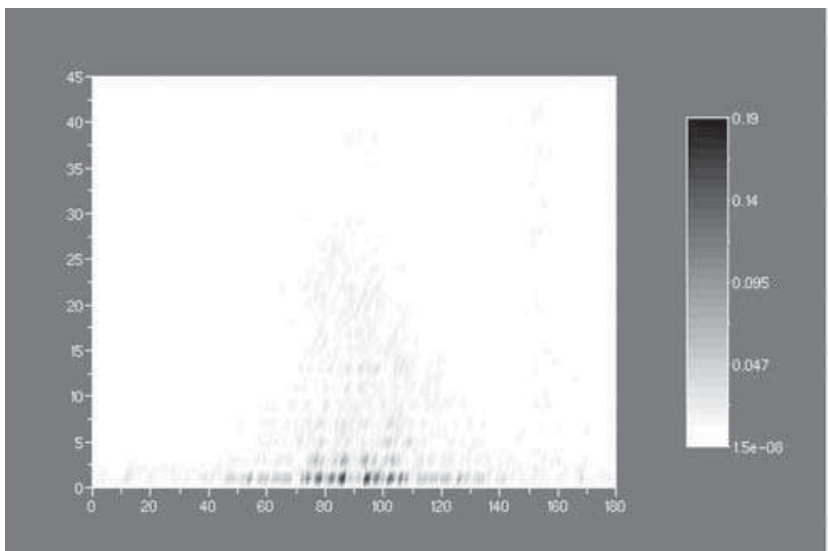

(a)

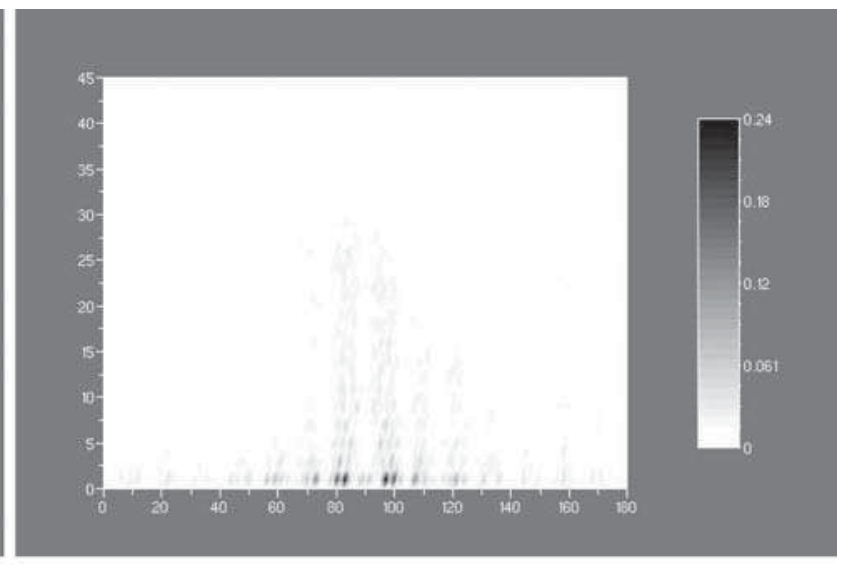

(b)

Fig. 23. VOR accuracy $\left({ }^{\circ}\right)$ of Doppler VOR for two implantation configurations (Fig. 21(a)). (a) Conf. 1. (b) Conf. 2.

bearing error for Conf. 1 is about $1.3^{\circ}$ as opposed to $2.8^{\circ}$ for Conf. 2.

These two figures confirm that the mast impact dominates as compared with the blade effects and that the Doppler VOR is far less sensitive to multipaths than conventional VOR whatever the implantation configurations.

\section{CONCLUSIONS}

We have built an electromagnetic model for the VHF frequencies of rotor blades based on a dielectric structure. We have shown that the conventional metal model is not suitable to describe this. Then, we have compared the impact of a three-blade rotor with the wind turbine's metal mast. The blade effects can be neglected as compared with the mast effects at weak elevation directions where the mast's scattered field is maximum (grazing angles for long distances from VOR).

Thanks to the knowledge of the scattered far field of a single blade and that of the mast, both computed using the integral method (method of moment), the scattered far field for each wind turbine, forming a wind farm, has been calculated. Then, the bearing error has been evaluated for the two kinds of VOR (Conventional and Doppler) and for several geometrical configurations of wind farms. From this study, no proper choice of geometrical configurations of a wind farm can be made. VOR error evolution can be evaluated for different parameters such as the distance from VOR or the number of wind turbines. The Doppler VOR seems to be a good solution to prevent VOR system from multipath.

Note 1: The scattered field at scatterer reference coordinate system is plotted for nacelle, blades and mast for the geometrical configuration described in the Fig. 12. Concerning the nacelle, the worst case (scattered field maximum for $\varphi_{i}-\varphi_{0}=90^{\circ}$ ) is for an angle $\varphi_{\text {inc }}=45^{\circ}$ and $\theta_{\text {inc }}=90^{\circ}$. The blade presents the orientation described in Fig. 13(a). For grazing angles, the scattered field by the nacelle is lower than one of the mast (Fig. 24). For other angles it is at the same order of magnitude that the scattered field by the blades or the mast (Fig. 25). 


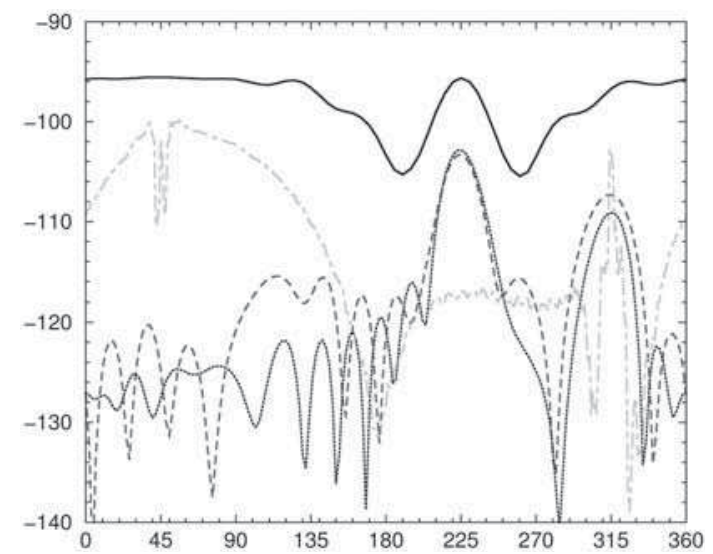

Fig. 24. Scattered field cut $(\mathrm{dBv} / \mathrm{m})$ for $\varphi_{\text {inc }}=45^{\circ}, \theta_{\text {obs }}=88^{\circ}$, $\varphi_{\mathrm{obs}}=\left[0\right.$ to $\left.360^{\circ}\right] .($ Mast $=$ solid line, Tree_blades: long dashed line, rounded nacelle $=$ dotted line, rectangular nacelle $=$ dashed line).

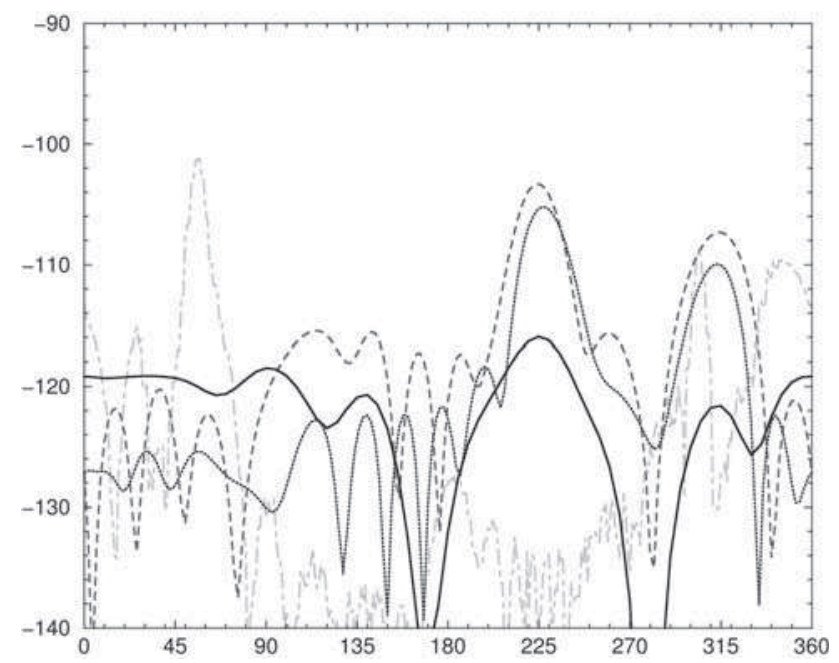

Fig. 25. Scattered field cut $(\mathrm{dBv} / \mathrm{m})$ for $\varphi_{\text {inc }}=45^{\circ}, \theta_{\text {obs }}=70^{\circ}$, $\varphi_{\text {obs }}=\left[0\right.$ to $\left.360^{\circ}\right]$. (Mast $=$ solid line, Tree_blades: long dashed line, rounded nacelle $=$ dotted line, rectangular nacelle $=$ dashed line).

Note 2: Locally, a field can always be represented by a spectrum of plane waves where the number of plane waves depends on the distance between the scattering object and the source and on the size of the object. Then, when the scatterer is in the near field area, the excitation can be described by a spectrum of plane waves.

Because the method of moment first calculates the equivalent current on the scattering object, the propagated electromagnetic field can be calculated from equivalent currents in all areas without distance restriction between the scatterer and the receiver. The far field scattering matrix used can be replaced by that of a near field.

Note 3: In the VHF band, when a flat ground is illuminated by a source with grazing angles, the coefficient of reflexion is equivalent to that of a conducting plan. According to image theory, a

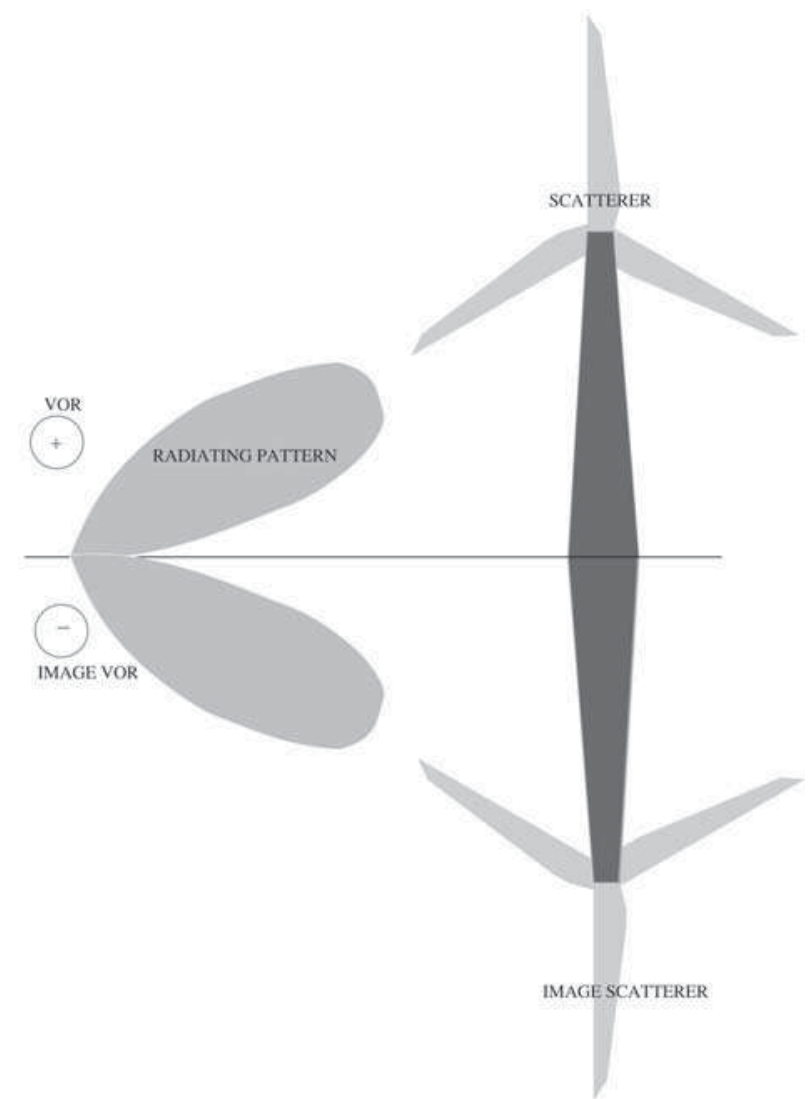

Fig. 26. Image theory.

conducting flat ground can be modeled by a second scattering object, called image object and an image source. Normally, a null field for the grazing angles appears as shown in Fig. 26.

If the ground between the VOR and the scatterer is rough or not flat, the reflected field decreases and for the grazing angles the total field is no longer null. In order to consider a worst case, we used an omnidirectional pattern for the VOR antenna which corresponds to a nonreflective ground between the VOR and the scatterer. Furthermore, to consider a reflective field by the ground from the scatterer, the image scatterer is illuminated by (image source) the omnidirectional pattern phase shifted by $180^{\circ}$. The incident field is modeled by two plane waves: one to illuminate the wind turbine when any reflexions occur on the ground between the VOR and the wind turbine: the other (with $180^{\circ}$ phase shift) to illuminate the image wind turbine to take into account flat ground between the wind turbine and the VOR receiver. Then the total scattered electrical field by (one blade, mast) one part of the wind turbine is calculated by the vectorial summation of the two scattered electric fields. This principle is repeated for all the elements constituting the wind turbine to obtain the total field scattered by a single wind turbine.

Note 4: For blade/blade or blade/mast interactions, a complementary study should be 
investigated to evaluate possible effects. On the other hand, for wind turbine/wind turbine interactions, no resonance effects can occur on bearing error results considering the space $(250 \mathrm{~m})$ between two closed wind turbines compared with wavelength.

\section{REFERENCES}

[1] Bendali, A., and Devys, C.

Calcul numerique de rayonnement de cornets électromagnétiques dont l'overture est partiellement remplie par un diélectriques.

[2] Duhoo, T Polytechnic Report, 1982.

Utilisation de la matrice de rotation des angles d'Euler dans l'etude de problemes de dimension 3.

UFR de physique, 95 (2001).

[3] Griffin, D. A.

Blade System Design Studies Vol. I: Composite Technologies for Large Wind Turbine Blades. SAND2002-1879, Kirkland, WA, July 2002.

[4] Quinet, D., and Odunaiya, S.

Calculations and analysis of signal processing by various navigation receiver architectures.

In Digital Avionics Systems Conference (2004 DASC04), Oct. 2004.
[5] Poupart, G. J.

Wind farms impact on radar aviation interests-Final report.

QinetiQ, Sept. 2003.

[6] Chisholm, D.

Broadcast communications limited.

Project west wind, compatibility with radio services, July 1, 2005.

[7] Butler, M. M., and Johnson, D. A

Feasibility of mitigating the effects of windfarms on primary radar.

ETSU W/14/00623/REP, DTI PUB URN No. 03976, 2003.

[8] BBC/RA/ITC

The impact of large building and structures (including wind farms) on terrestrial television reception, June 27, 2002.

[9] Sengupta, D. L., and Senior, T. B. A

Electromagnetic interference from wind turbines.

In D. A. Sepra (Ed.), Wind Turbine Technology, ASME Press, 1994, ch. 9.

[10] CCTR, Hélimax

Information technique sur l'evaluation des impacts potentiels des eoliennes sur les systemes de radiocommunication.

Energie Inc. Report, Montreal, Aug. 10, 2005. 

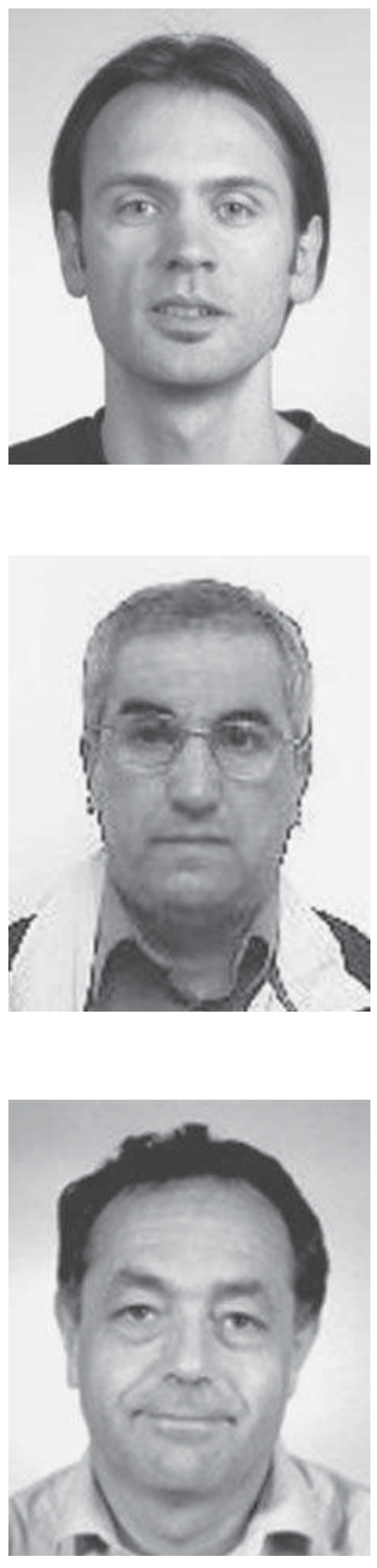

Christophe Morlaas received the Ph.D. degree in 2000 from ENSAE (Superior National School of Aeronautical and Spatial) in optoelectronic engineering.

He has a system engineer on spatial programs until 2002. Since 2002 he has been a teacher /researcher in the LETA laboratory of ENAC (National School of Civil Aviation) in electromagnetism domains. His research interests are in the fields of aeronautical communication and navigation systems, electromagnetic modeling and propagation.

M. Barek Fares received the Ph.D. degree in numerical analysis from the University of Grenoble, France, in 1982.

From 1982 to 1987, he was appointed assistant professor in the Department of Numerical Analysis, University of Casablanca, Morroco. Since 1992 he has been a senior research scientist at the CERFACS (European Center for Research and Advanced Training in Scientific Computation) Toulouse, France. His research interests include numerical techniques in computational electromagnetic methods based on integral equation.

Bernard Souny received the Senior Engineer Diploma from ENAC (National School of Civil Aviation) in 1973 and the Ph.D. degree in electronics from the Institut National Polytechnique de Toulouse (INPT) in 1993.

He is chief of LETA Laboratory of ENAC. His research interest include numerical techniques in computational electromagnetic, antenna design, and propagation models. 